\title{
Desain Kansei Monitoring System Pasien Rawat Inap
}

\author{
Ari Subowo" ${ }^{* 1}$, Widyastuti ${ }^{2}$ \\ ${ }^{1,2}$ Program Studi Teknik Industri, Sekolah Tinggi Teknologi Muhammadiyah Kebumen \\ Jl. Indrakila No. 38A Kebumen Telp. (0287) 6601039 \\ Email: "1 ariesubowo@ gmail.com, ${ }^{2}$ widyas2tix@ gmail.com
}

\begin{abstract}
Abstrak
Kualitas rumah sakit sangat dipengaruhi oleh kualitas layanan terhadap pasien. Salah satu permasalahan yang dikeluhkan pasien mengenai pelayanan rumah sakit adalah kurang responsifnya perawat dalam memonitor pasien rawat inap. Keluarga pasien harus aktif memonitor pasien dan selanjutnya menghubungi perawat ketika terjadi permasalahan. Kondisi ini salah satunya disebabkan masih kurangnya peralatan yang dapat digunakan oleh perawat untuk melakukan monitoring pasien dari jarak jauh. Untuk mengatasi permasalahan tersebut, dalam penelitian ini dilakukan desain sistem monitoring pasien rawat inap. Proses desain dilakukan dengan metode Kansei Engineering. Langkah awal penelitian adalah identifikasi kata kansei dengan responden pasien, perawat dan dokter. Berdasarkan hasil survei diperoleh dua kata kansei yang valid dan reliabel yaitu aman dan mudah digunakan. Kedua kata kansei dipetakan menjadi desain parameter, sehingga diperoleh desain perangkat sistem yang terdiri dari modul sensor suhu, pulse sensor, infrared sensor, signal conditioning modul, point router access dan komputer. Tahap selanjutnya adalah pembuatan prototype dan pengujian prototype. Hasil pengujian prototype menunjukkan bahwa perangkat sistem monitoring yang didesain dapat memenuhi kebutuhan pengguna.
\end{abstract}

Kata kunci: kansei, kualitas layanan, sistem monitoring pasien

\section{PENDAHULUAN}

Rumah Sakit merupakan bagian menyeluruh dari suatu organisasi medis yang memberikan layanan dibidang kesehatan secara lengkap kepada masyarakat baik kuratif maupun rehabilitatif. Kualitas rumah sakit sangat ditentukan oleh kualitas layanan yang diberikan terhadap pasien (Sari \& Wulandari, 2014). Salah satu sumber daya layanan di rumah sakit adalah perawat. Kualitas layanan perawat terhadap pasien dapat menumbuhkan rasa percaya terhadap pasien, yang dapat memberikan dampak positif terhadap hasil kesehatan dan daya dukung terhadap nilai pemasaran (Rutherford, 2014). Namun demikian kurang responsifnya perawat dalam memonitor pasien rawat inap menjadi salah satu permasalahan yang dikeluhkan pasien. Kondisi ini salah satunya disebabkan masih kurangnya perangkat yang dapat membantu perawat dalam memonitor pasien dari jarak jauh. Untuk itu diperlukan suatu peralatan yang dapat membantu perawat dalam melakukan monitoring pasien sehingga keluarga pasien tidak harus aktif menghubungi perawat dan memberitahukan kondisi pasien.

Peralatan yang dapat membantu pemantauan kondisi pasien adalah sistem instrumentasi elektronik dengan fungsi monitoring yang real time (Nirmalasari, Putra \& Prastowo, 2013). Peralatan tersebut menggabungkan antara sistem elektronika dan sistem teknologi informasi. Agar perangkat ini dapat diaplikasikan dengan baik maka diperlukan desain yang tepat. Salah satu metode desain efektif untuk menterjemahkan perasaan dan keinginan emosional pengguna 
menjadi desain parameter produk adalah Kansei Engineering (Nagamachi \& Lokman, 2016). Metode ini telah menghasilkan beberapa desain produk diantaranya desain sun glasses (Chuan et. al, 2013), desain kerajianan logam dan perhiasan (Chiang et.al, 2012), desain handuk katun basah (Soeta et.al, 2012), warna background pada digital storytelling (Yussof, Abas \& Paris, 2012), real estate (Llinares \& Page, 2011), dan interior kereta api (Lanzotti \& Tarantino, 2008). Mengacu pada hal tersebut, maka tujuan penelitian ini adalah mendesain sistem monitoring pasien rawat inap dengan metode kansei engineering.

\section{METODE PENELITIAN}

Penelitian ini terdiri atas tiga tahapan utama yaitu identifikasi kata kansei, pemetaan kata kansei menjadi desain parameter dan pengujian desain. Identifikasi kata kansei dilaksanakan dengan metode survei di Klinik Aqila, Mergosono, Kecamatan Buayan, Kebumen dengan responden pasien, perawat dan dokter. Dalam tahap ini diidentifikasi kebutuhan pengguna yang meliputi (Lokman, 2010):

a. Feeling, yaitu perasaaan yang diinginkan pengguna ketika menggunakan produk

b. Image, yaitu gambaran/ deskripsi fisik produk yang diinginkan pengguna

c. Impression, yaitu kesan yang diinginkan pengguna terhadap produk yang akan dibuat

Tahap kedua ialah pemetaan kata kansei menjadi desain parameter dengan menggunakan metode Kansei Engineering Tipe 1. Konsep produk target dipetakan menjadi konsep yang lebih detail berdasarkan kata-kata kansei sehingga diperoleh desain fisik (Nagamachi \& Lokman, 2016). Sedangkan tahap pengujian desain sistem monitoring pasien rawat inap diwujudkan dalam bentuk prototype untuk kemudian dilakukan pengujian. Proses pengujian juga dilakukan di Klinik Aqila, dengan responden 1 orang pasien, 2 orang perawat dan 1 orang dokter. Hasil pengujian selanjutnya dianalisis menggunakan analisis deskriptif non parametrik.

\section{HASIL DAN PEMBAHASAN}

\section{Identifikasi Kata Kansei}

Berdasarkan hasil survei diperoleh dua kata kansei yang valid dan reliabel. Rekapitulasi pengujian validitas dan reliabilitas terhadap dua kata kansei disajikan pada Tabel 1.

Tabel 1. Hasil Kata Kansei

\begin{tabular}{llccc}
\hline No & \multicolumn{1}{c}{ Kata kansei } & $\begin{array}{c}\text { Reliabilitas } \\
(\alpha)\end{array}$ & $\begin{array}{c}\text { Validitas } \\
(\rho)\end{array}$ & Keterangan \\
\hline 1. & Mudah digunakan & 0,78 & 0,582 & Valid \\
2. & Aman & 0,78 & 0,580 & Valid \\
\hline
\end{tabular}

\section{Pemetaan Kata Kansei Menjadi Desain Parameter}

Sistem monitoring pasien rawat inap yang mudah digunakan diwujudkan 
dengan alat yang dapat memonitor suhu, detak jantung dan cairan infus. Ketiga data tersebut dapat diakses dari ruang perawat tanpa harus mengunjungi ruang pasien. Komponen perangkat terdiri dari modul sensor suhu, pulse hear rate sensor, infrared obstacle sensor, signal conditioning modul, akses point router dan komputer.

Kriteria peralatan yang aman diwujudkan dengan memperhatikan letak sensor, bahan sensor, bahan perekat alat sensor ke tubuh dan casing sensor. Letak sensor terbagi menjadi tiga bagian yaitu di pergelangan tangan untuk sensor detak jantung, ketiak untuk sensor suhu dan tiang infus untuk sensor infus. Bahan sensor suhu dan detak jantung menggunakan waterproof sensor, yang bertujuan untuk mencegah interferensi keringat pasien terhadap alat. Agar kedua sensor tersebut nyaman bagi pasien maka bahan perekat alat sensor ke tubuh dibuat menggunakan kain flanel. Hasil pemetaan kedua kata kansei menjadi desain parameter secara sistematis dijabarkan dalam Tabel 2 dan Tabel 3.

Tabel 2. Pemetaan Kata Kansei Kemudahan Penggunaan

\begin{tabular}{lll}
\hline Kata Kansei & Orde 1 & \multicolumn{1}{c}{ Desain Parameter } \\
\hline Mudah & Memonitor suhu & Modul sensor suhu DS1820 \\
\cline { 2 - 3 } digunakan & $\begin{array}{l}\text { Memonitor detak } \\
\text { jantung }\end{array}$ & Pulse heart rate sensor \\
\cline { 2 - 3 } & Memonitor infus & Infra red obstacle sensor \\
\cline { 2 - 3 } & Diakses dari ruang & Signal conditioning modul (wireless lan \\
perawat & $\begin{array}{l}\text { port, microcontroler nodemcu, 1 port } \\
\text { mini usb, port psu, power bank 5V) }\end{array}$ \\
& & Access point router \\
\cline { 2 - 2 } & & Komputer \\
\hline
\end{tabular}

Tabel 3. Pemetaan Kata Kansei Aman

\begin{tabular}{llll}
\hline Kata Kansei & \multicolumn{1}{c}{ Orde 1 } & \multicolumn{1}{c}{ Orde 2 } & \multicolumn{1}{c}{ Desain Parameter } \\
\hline Aman & Letak sensor & Sensor detak jantung & Pergelangan tangan \\
\cline { 3 - 4 } & & Sensor suhu & Ketiak \\
\cline { 3 - 4 } & & Sensor infus & Tiang infus \\
\cline { 2 - 4 } & Bahan sensor & Sensor suhu & Waterproof sensor \\
\cline { 2 - 3 } & Sensor detak jantung & Waterproof sensor \\
\cline { 2 - 4 } $\begin{array}{l}\text { Bahan } \\
\text { perekat alat } \\
\text { sensor ke } \\
\text { tubuh }\end{array}$ & Sensor suhu & Kain flanel \\
\cline { 2 - 3 } & Sensor detak jantung & Kain flanel \\
& Sasing & Sensor infrared & Casing plastik \\
sensor & & polipropilena \\
\hline
\end{tabular}

\section{Rangkaian Sistem}

Perangkat sistem yang terdiri dari modul sensor suhu, pulse heart rate 
sensor, infrared obstacle sensor, signal conditioning modul, akses point router dan komputer yang bekerja dengan alur proses seperti dijelaskan pada Gambar 1 . Rangkaian perangkat sistem monitoring pasien secara sistematis ditampilkan pada Gambar 2. Sistem kerja perangkat tersebut terdiri dari proses kerja sensor, proses signal conditioning dan proses monitoring.

Sensor berguna untuk mendeteksi sinyal suhu, detak jantung dan cairan infus pasien. Proses deteksi sinyal suhu pasien menggunakan sensor suhu jenis DS1820 waterprof temperature, dengan panjang kabel 1 (satu) meter yang memungkinkan peletakan sensor secara fleksibel pada tubuh pasien. Alat ini mengubah sinyal suhu yang berada pada tubuh pasien menjadi sinyal listrik sehingga lebih mudah diproses dalam signal conditioning modul. Proses pendeteksian detak jantung menggunakan pulse heart rate sensor. Proses pengukuran dilakukan dengan cara mendeteksi volume aliran darah dalam nadi. Tekanan aliran darah dalam pembuluh nadi membuat volume darah berubah-ubah, hal ini yang dimanfatkan untuk mendeksi jumlah detak jantung pasien. Proses pemantauan aliran infus dilakukan menggunakan sensor infrared obstacle. Modul sensor ini mempunyai sensor pemancar dan penerima. Sinyal infra merah yang dipancarkan akan mengenai tetesan cairan infus, dan memantulkan sinyal ke penerima. Proses ini digunakan untuk mengetahui jumlah tetesan infus per menit dan mengetahui infus masing mengalir atau tidak.

Proses pengolahan sinyal dari sensor menjadi sebuah sinyal informasi dalam sistem ini menggunakan mikrokontroler Node MCU esp 8266. Mikrokontroler ini dilengkapi dengan sebuah port WIFI yang memungkinan data dikirimkan melalui jaringan internet wireless (WLAN). Sinyal dari sensor yang sudah diproses dalam signal conditioning dikirim ke dalam server. Aplikasi server yang digunakan adalah XAMPP, yaitu sebuah paket aplikasi yang di dalamnya terdapat apache dan mysql. Apache digunakan untuk aplikasi web server dan mysql digunakan sebagai sistem penyimpanan data. Data-data yang telah masuk dalam server dapat diakses oleh komputer maupun gadget lain yang sudah dilengkapi dengan browser. Data tersebut dapat diwujudkan dalam bentuk angka maupun grafik yang dapat diakses secara fleksibel dengan ketentuan tersambung dalam satu jaringan, baik melalui wireless LAN atau Wire secara real time.

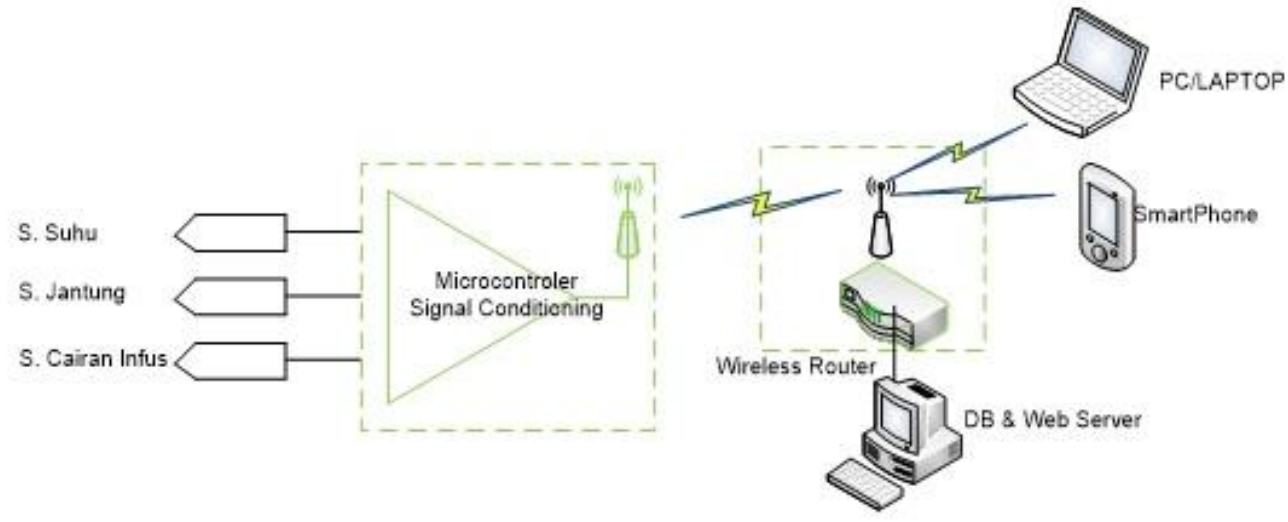

Gambar 1. Alur Proses Sistem Monitoring Pasien 


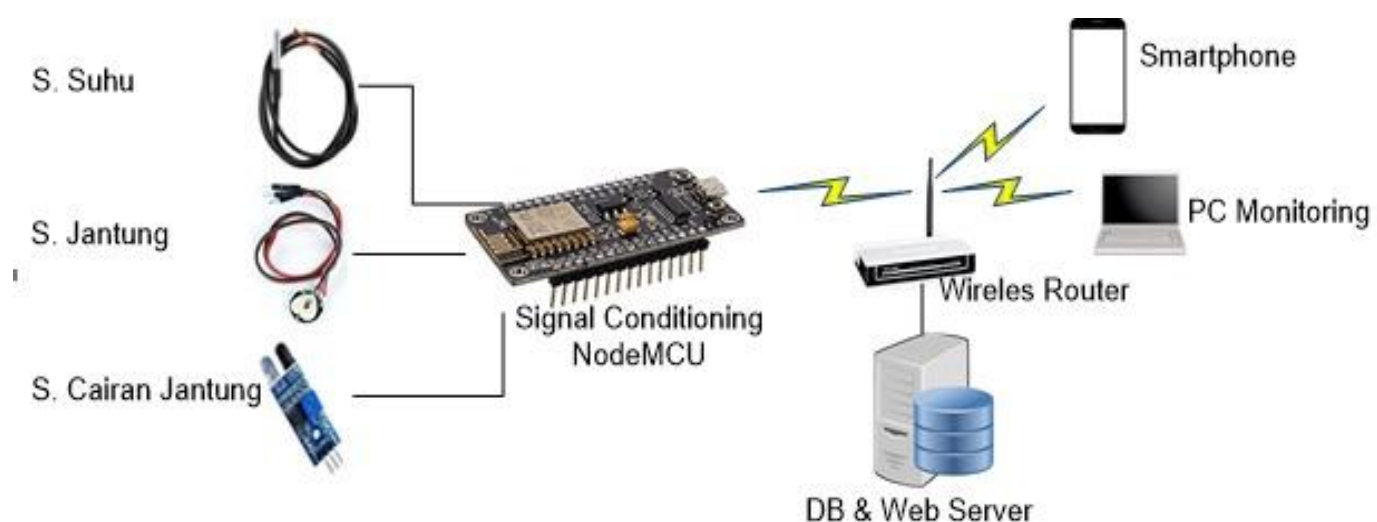

Gambar 2. Rangkaian Perangkat Sistem Monitoring Pasien

\section{Prototype}

Berdasarkan desain parameter di atas, dibuat prototype yang terdiri dari perangkat sensor suhu, sensor detak jantung, sensor cairan infus seperti ditampilkan pada Gambar 3, Gambar 4, dan Gambar 5. Perangkat sistem pengolah data terdiri dari signal conditioning modul dan access point router sebagaimana ditampilkan pada Gambar 6 dan Gambar 7.

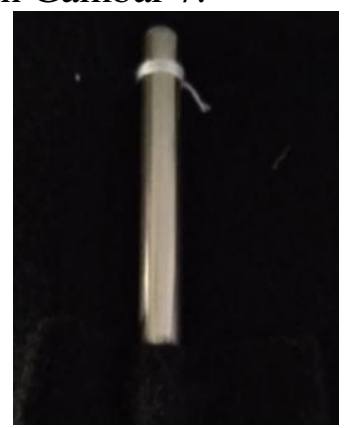

Gambar 3. Sensor Suhu

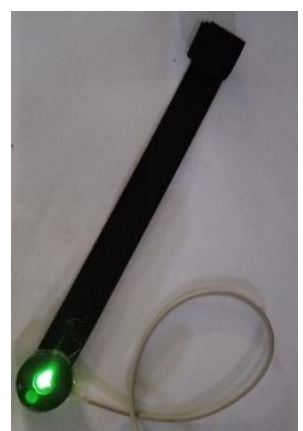

Gambar 4. Sensor Detak Jantung 


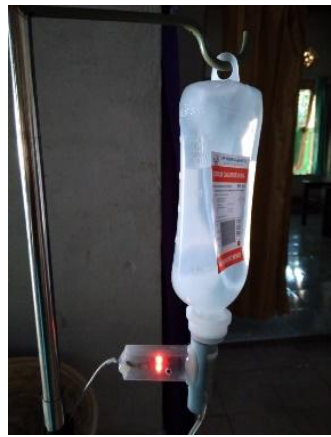

Gambar 5. Sensor Cairan Infus
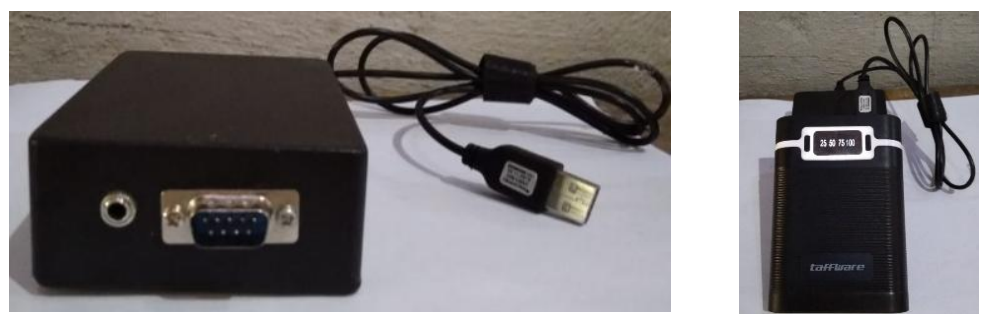

Gambar 6. Signal Conditioning Modul

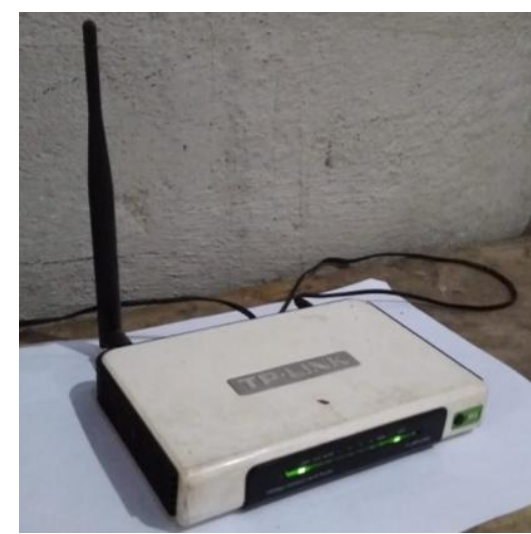

Gambar 7. Access Point Router

Hasil monitoring suhu, detak jantung dan cairan infus dalam layar monitor ditampilkan dalam bentuk grafis sebagaimana Gambar 8. Bentuk print out data monitoring data pasien terdiri dari data suhu dalam ${ }^{\circ} \mathrm{C}$, detak jantung dalam $\mathrm{Bpm}$ dan data infus dalam tetes/menit seperti dijelaskan pada Gambar 9.

\section{Pengujian Prototype}

Pengujian dilakukan untuk memonitor satu pasien rawat inap selama satu hari, dengan pengawasan oleh dua orang perawat dan satu orang dokter. Dari pengujian tersebut diperoleh hasil bahwa perangkat sistem monitoring pasien rawat inap tersebut dapat berjalan sesuai dengan fungsinya sehingga perawat dan dokter sangat terbantu dalam memonitor suhu, detak jantung dan cairan infus pasien. Perangkat tersebut aman digunakan, tidak memberikan efek samping dan tidak mempersulit ruang gerak pasien. 


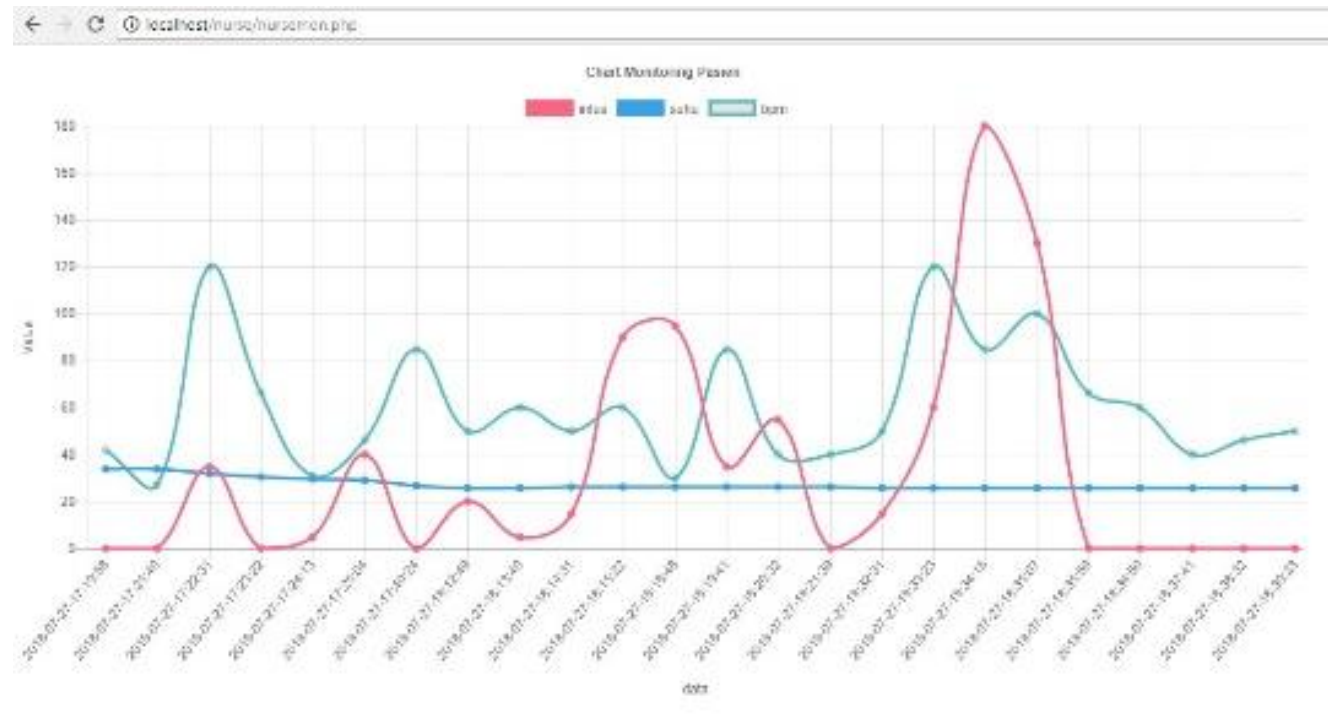

Gambar 8. Tampilan Monitor Data Pasien

\begin{tabular}{|c|c|c|c|c|c|}
\hline $\mathrm{N}_{0}$ & 0 Suhu $\left({ }^{*} \mathrm{c}\right)$ & Bpm (pulsmenit) & t) Infus (tetes imenit) & Tanggal & Jam \\
\hline 1 & 36.6 & 70 & 60 & $2018-07-15$ & 20:21:00 \\
\hline 2 & 36.6 & 71 & 60 & $2018-07-15$ & $20: 21: 00$ \\
\hline 3 & 36.6 & 70 & 60 & $2018-07-15$ & $20: 31$ \\
\hline 4 & 36.6 & 70 & 60 & $2018-07-15$ & $20: 38: 00$ \\
\hline 5 & 36.6 & 70 & 60 & $2018-07-15$ & $20: 40: 08$ \\
\hline 6 & 36.9 & 70 & 35 & $2018-07-16$ & $14: 07: 53$ \\
\hline 7 & 36.9 & 70 & 50 & $2018-07 \cdot 16$ & 14:26:03 \\
\hline 8 & 36.9 & 70 & 50 & $2018-07-16$ & $14: 26: 14$ \\
\hline 9 & 36.9 & 70 & 50 & $2018-07-16$ & $14: 26$ \\
\hline 10 & 36.9 & 70 & 50 & $2018-07 \cdot 16$ & $14: 26: 35$ \\
\hline 11 & 36.9 & 70 & 50 & $2018-07 \cdot 16$ & $14: 26: 46$ \\
\hline 12 & 36.9 & 70 & 50 & $2018-07-16$ & 14.26 .56 \\
\hline 13 & 36.9 & 70 & 50 & $2018-07-16$ & 14:27:07 \\
\hline
\end{tabular}

Gambar 9. Tampilan Print Out Data Pasien

\section{KESIMPULAN}

Berdasarkan hasil di atas dapat disimpulkan bahwa hasil desain kansei monitoring sistem pasien rawat inap yang terdiri dari perangkat sistem berupa modul sensor suhu, pulse hear rate sensor, infrared obstacle sensor, signal conditioning modul, akses point router dan komputer telah memenuhi kriteria 
aman serta mudah digunakan bagi pengguna.

\section{SARAN}

Pada penelitian selanjutnya diharapkan dapat dikaji lebih jauh tentang sistem sensor cairan yang tidak mudah terpengaruh oleh intensitas cahaya di sekitar sehingga hasil monitor lebih akurat.

\section{UCAPAN TERIMA KASIH}

Penulis mengucapkan terimakasih kepada Direktorat Riset dan Pengabdian Masyarakat, Direktorat Jenderal Penguatan Riset dan Pengembangan Kementerian Riset, Teknologi dan Pendidikan Tinggi sebagai penyandang dana dalam pelaksanaan penelitian ini sesuai dengan Kontrak Penelitian Tahun Anggaran 2018.

\section{DAFTAR PUSTAKA}

Chiang, H.J., Liang, J.C., Hwu, T.J. and Masatake, N., 2012, The study of metalwork and jewelry products design education integrates with kansei design, International Journal of Kansei Information, 3(1), pp.7-23.

Chuan, N.K., Sivaji, A., Shahimin, M.M. and Saad, N., 2013, Kansei engineering for e-commerce sunglasses selection in Malaysia, Procedia-Social and Behavioral Sciences, 97, pp.707-714.

Lanzotti, A. and Tarantino, P., 2008, Kansei engineering approach for total quality design and continuous innovation, The TQM Journal, 20(4), pp.324-337.

Llinares, C. and Page, A.F., 2011, Kano's model in Kansei Engineering to evaluate subjective real estate consumer preferences, International Journal of Industrial Ergonomics, 41(3), pp.233-246.

Lokman, A.M., 2010, Design \& emotion: The kansei engineering methodology. Malaysian Journal of Computing, 1(1), pp.1-11.

Nagamachi, M. and Lokman, A.M., 2016, Innovations of Kansei engineering, CRC Press.

Nirmalasari, I., Putra, A.E. and Prastowo, B.N., 2013, Purwarupa Alat Ukur Daya Listrik Berbasis Netduino Plus, IJEIS (Indonesian Journal of Electronics and Instrumentation Systems), 5(1), pp.21-30.

Rutherford, M.M., 2014, The value of trust to nursing, Nursing Economics, 32(6), p.283.

Sari, A.K. and Wulandari, R.D., 2014, Penilaian Kepuasan Pasien terhadap Mutu Pelayanan Instalasi Rawat Jalan RS HS Samsoeri Mertojoso Surabaya, Jurnal Administrasi Kesehatan Indonesia, 2(4), pp.235-42. 
Soeta, Y., Kitamoto, T., Hasegawa, H. and Kasuga, M., 2012, Study on Factors of Favorable Wet Cotton Hand Towels "Oshibori", Kansei Engineering International Journal, 11(1), pp.19-25.

Yussof, R.L., Abas, H. and Paris, T.N.S.T., 2012, Affective engineering of background colour in digital storytelling for remedial students, ProcediaSocial and Behavioral Sciences, 68, pp.202-212. 